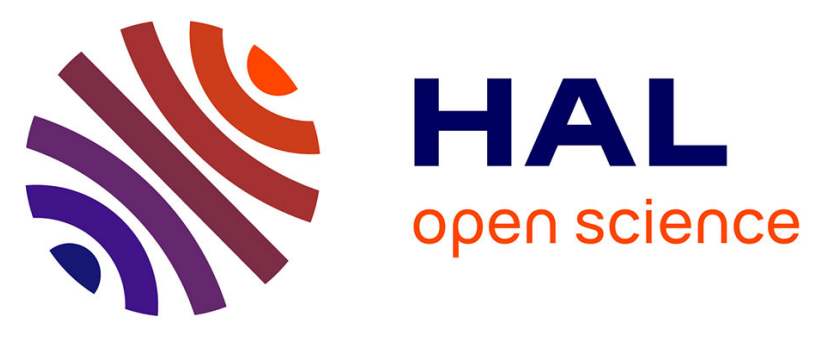

\title{
A comparison of the nutritional physiology and gut microbiome of urban and rural house sparrows (Passer domesticus)
}

Alice Gadau, Meli’Sa S. Crawford, Roman Mayek, Mathieu Giraudeau, Kevin

J. Mcgraw, Corrie M. Whisner, Christina Kondrat-Smith, Karen L. Sweazea

\section{To cite this version:}

Alice Gadau, Meli'Sa S. Crawford, Roman Mayek, Mathieu Giraudeau, Kevin J. Mcgraw, et al.. A comparison of the nutritional physiology and gut microbiome of urban and rural house sparrows (Passer domesticus). Comparative Biochemistry and Physiology - Part B: Biochemistry and Molecular Biology, 2019, 237, pp.110332. 10.1016/j.cbpb.2019.110332 . hal-02468856

\section{HAL Id: hal-02468856 \\ https://hal.umontpellier.fr/hal-02468856}

Submitted on 27 Nov 2020

HAL is a multi-disciplinary open access archive for the deposit and dissemination of scientific research documents, whether they are published or not. The documents may come from teaching and research institutions in France or abroad, or from public or private research centers.
L'archive ouverte pluridisciplinaire HAL, est destinée au dépôt et à la diffusion de documents scientifiques de niveau recherche, publiés ou non, émanant des établissements d'enseignement et de recherche français ou étrangers, des laboratoires publics ou privés. 


\title{
A comparison of the nutritional physiology and gut microbiome of urban and rural house sparrows (Passer domesticus)
}

\author{
Alice Gadau ${ }^{\mathrm{a}}$, Meli'sa S. Crawford ${ }^{\mathrm{a}}$, Roman Mayek ${ }^{\mathrm{b}}$, Mathieu Giraudeau ${ }^{\mathrm{a}, \mathrm{c}, \mathrm{d}}$, Kevin J. McGraw ${ }^{\mathrm{a}}$, \\ Corrie M. Whisner ${ }^{\mathrm{b}}$, Christina Kondrat-Smith ${ }^{\mathrm{e}}$, Karen L. Sweazea ${ }^{\mathrm{a}, \mathrm{b}, *}$ \\ ${ }^{a}$ School of Life Sciences, Arizona State University, USA \\ ${ }^{\mathrm{b}}$ College of Health Solutions, Arizona State University, USA \\ ${ }^{\mathrm{c}}$ CREEC, 911 Avenue Agropolis, BP 6450134394 Montpellier Cedex 5, France \\ d MIVEGEC, UMR IRD/CNRS/UM 5290, 911 Avenue Agropolis, BP 6450134394 Montpellier Cedex 5, France \\ e Arizona Game and Fish Department, USA
}

Keywords:

Physiology

Nutrition

Gut microbiome

Urban

Avian

Rural

\begin{abstract}
A B S T R A C T
Urbanization influences food quality and availability for many wild species, but our knowledge of the consequences urbanization has on the nutritional physiology of these animals is currently limited. To fill this gap, we captured House Sparrows (Passer domesticus) from rural and urban environments and hypothesized that increased access to human refuse in urban areas may significantly alter the gut microbiome and nutritional physiology of Sparrows. While there were no significant differences in circulating triglycerides or free glycerol concentrations between populations, urban birds had significantly greater blood glucose concentrations, which suggests greater circulating glucagon concentrations, accessibility to carbohydrates, and/or higher rates of gluconeogenesis in an urban setting. Rural birds had significantly more plasma uric acid, suggesting that they may metabolize more proteins or experience lower inflammation than urban birds. Rural birds also had significantly higher liver free glycerol concentrations, indicating that they metabolize more fat than urban birds. There were no significant differences in the relative abundance of gut microbial taxa at the phyla level between the two populations, but linear discriminant analysis effect size (LEfSe) showed that urban House Sparrows were more enriched with class- and order-level microbes from the phylum Proteobacteria, which are implicated in several mammalian intestinal and extra-intestinal diseases. These findings demonstrate that urbanization significantly alters the nutritional physiology and the composition of the gut microbiome of House Sparrows.
\end{abstract}

\section{Introduction}

According to a 2018 United Nations report, 55\% of the world's human population inhabits urban areas and this number is predicted to rise to $68 \%$ by 2050 (United Nations, 2018). In North America, in particular, approximately $82 \%$ of the population resides in urban areas (United Nations, 2018). Living in urban environments can pose risks to both humans and animals, including overpopulation, infection with transmissible diseases, exposure to pollutants, habitat alteration, and shifts in food availability and diversity (Evans et al., 2009; Pollack et al., 2017). Birds in particular have been considered a useful biomonitor of the effects of anthropogenic environmental disturbances on the health of urban-dwelling species (Pollack et al., 2017), since approximately $20 \%$ of the ca. 10,000 recognized avian species have been able to colonize our cities (Aronson et al., 2014).
Reports indicate that one-third to two-thirds of households in Great Britain, New Zealand, and the United States provide food for wild birds (Cox and Gaston, 2016; Cowie and Hinsley, 1988; Davies et al., 2009; Galbraith et al., 2014; Martinson and Flaspohler, 2003). Bread is reportedly the most common food provided for birds, followed by seeds (Galbraith et al., 2015), although urban birds also have access to unintentional food sources in the form of human refuse. Contrary to popular belief, recent studies show that feeding wild birds can have unintended and sometimes detrimental consequences for them. Multiple studies have shown that granivorous House Sparrows (Passer domesticus) often dominate feeders (Francis et al., 2018; Galbraith et al., 2014, 2015), which can reduce time spent foraging and impact body condition, reproduction, survival, disease transmission, and community structure, and may lead to malnutrition (Galbraith et al., 2014, 2015, 2016).

\footnotetext{
* Corresponding author.

E-mail address: Karen.Sweazea@asu.edu (K.L. Sweazea).
} 
Whereas rural House Sparrows consume diets mainly consisting of human-produced grains (corn, oats, wheat) and insects, urban conspecifics consume a more diverse diet of human-derived food waste, commercial birdseeds, insects, and grains (Gavett and Wakeley, 1986; Martin and Fitzgerald, 2005). These differences in diet have been shown to increase intake and circulating levels of protein and fat in urban House Sparrows compared to rural conspecifics (Gavett and Wakeley, 1986), although studies have shown that House Sparrows captured in more urbanized areas are smaller and weigh less than rural conspecifics (Meillere et al., 2015). A recent study examining blood samples from hundreds of House Sparrows captured from rural, suburban and urban areas in Spain found that urban birds had higher oxidative stress and higher levels of antioxidant enzyme activity, but lower antioxidant capacity compared to those from other habitats (Herrera-Duenas et al., 2017). Poor dietary quality (and low availability of dietary antioxidants) was highlighted as a potential mediator of the increased oxidative stress in urban House Sparrows (Herrera-Duenas et al., 2017).

Urbanization, as well as the type of foods available to birds, have been shown to reduce gut microbial species diversity in House Sparrows and to specifically reduce the abundance of Actinobacteria (Teyssier et al., 2018). While this prior study examined the impact of urbanization on the gut microbiome of House Sparrows, the authors did not examine the nutritional physiology of the birds. The purpose of the present study was to compare the gut microbiome and nutritional physiology of House Sparrows living in urban and rural areas by measuring carbohydrate, triglyceride and protein catabolism. Because urban House Sparrows have greater access to human-derived foods in the form of birdseeds and breads, we hypothesized that they would have a reduced gut microbial diversity as well as higher plasma glucose concentrations and lower uric acid and triglyceride concentrations when compared to rural Sparrows.

\section{Material and methods}

\subsection{Animal model and sample preparation}

From October - December 2016, adult male and female House Sparrows were captured using potter traps baited with wild bird seeds or mist nets between sunrise and $10 \mathrm{AM}$ from urban yards around the ASU Tempe campus ( $n=4$ female, 3 male; $33.44^{\circ} \mathrm{N},-111.93^{\circ} \mathrm{W}$ ) and rural area ranch properties adjacent to Sonoran desert scrub $(n=6$ female, 7 male; $33.78^{\circ} \mathrm{N},-112.53^{\circ} \mathrm{W}$; Fig. 1). Birds were transported to the laboratory at Arizona State University in cloth bags with drawstring closures in an air-conditioned vehicle to minimize stress. As transport may have induced stress in the animals, birds were allowed to rest in their cloth bags for $1 \mathrm{~h}$ in a dimly lit quiet room prior to being weighed with a triple beam animal balance to the nearest $0.5 \mathrm{~g}$ and collecting $50 \mu \mathrm{L}$ of blood from the brachial vein. Following euthanasia (sodium pentobarbital, $200 \mathrm{mg} / \mathrm{kg}$, i.p.), cardiac plasma, liver, and fecal samples obtained from the colon (to avoid uric acid contamination using voided fecal samples) were collected. Whole blood samples were centrifuged at $14,000 \mathrm{rpm}$ for $10 \mathrm{~min}$ at $4{ }^{\circ} \mathrm{C}$ to separate blood cells from plasma. Tissues and plasma samples were frozen at $-80^{\circ} \mathrm{C}$ until analyses. All animal protocols were approved by the Institutional Animal Care and Use Committee of Arizona State University (16-1468R) and collected under a scientific collecting permit from the Arizona Game and Fish Department (SP732787).

\subsection{Plasma metabolites}

Plasma glucose concentrations were assessed using a commercially available kit according to the manufacturer's protocol (Cat. No. 10009582; Cayman Chemical, Ann Arbor, MI) with the exception of diluting samples 1:15 with sample buffer prior to the assay to bring the glucose concentrations within range of the standard curve. The average intra-assay coefficient of variation for glucose was $1.46 \pm 0.27 \%$. Uric acid is the main end product of nitrogen catabolism in birds, and levels change in response to dietary protein intake and catabolism (Cohen et al., 2009; Machin et al., 2004; Tsahar et al., 2006). It is also the most abundant antioxidant found in birds (Seaman et al., 2008; Stinefelt et al., 2005; Machin et al., 2004; Simoyi et al., 2002; Klandorf et al., 2001). For these reasons, we measured plasma uric acid concentrations using a kit (Cat. No. DIUA-250; Bioassay Systems, Hayward, CA). The average intra-assay coefficient of variation was $1.04 \pm 0.3 \%$. Plasma free glycerol and triglycerides were measured using a kit purchased from Sigma Aldrich (TR0100, St. Louis, MO). The average intra-assay coefficient of variation was $1.62 \pm 0.26 \%$ and $2.24 \pm 0.38 \%$, respectively. All samples were run in duplicate on the same plate for each assay and the percent intra-assay coefficient of variation reflects the duplicate measures.

\subsection{Liver free glycerol and triglycerides}

Concentrations of liver free glycerol and triglycerides were measured following Norris et al. (2003). Briefly, between 100 and $300 \mathrm{mg}$ of liver was lysed using $350 \mu \mathrm{L}$ ethanolic potassium hydroxide and incubated overnight at $55^{\circ} \mathrm{C}$. The solution was brought to $1 \mathrm{~mL}$ with 1:1 $\mathrm{H}_{2} \mathrm{O}: \mathrm{EtOH}$. The saponified sample was then centrifuged, and the resulting supernatant was collected and transferred to a new tube. The supernatant was brought up to $1.2 \mathrm{~mL}$ with $1: 1 \mathrm{H}_{2} \mathrm{O}$ :EtOH. Of this resulting mixture, $200 \mu \mathrm{L}$ was removed and mixed with $215 \mu \mathrm{L}$ of $1 \mathrm{M}$ $\mathrm{MgCl}_{2}$. Samples were then assayed for free glycerol using a commercially available kit according to the manufacturer's protocols (Cat. No. TR0100; Sigma Aldrich), and triglyceride concentration was calculated from the glycerol concentrations using the following equation: Triglyceride $(\mathrm{mg} / \mathrm{g}$ tissue $)=$ Glycerol $(\mathrm{mg} / \mathrm{dL}) \times(10 / 30) \times(415 / 200) \times$ (0.012 dL/g tissue mass).

The average intra-assay coefficient of variation was $0.89 \pm 0.11 \%$ for the duplicate measurements of each sample on the 96-well plate.

\subsection{Liver glycogen}

Liver glycogen was measured according to the phenol-sulfuric acid technique (Lo et al., 1970). Frozen liver samples (35-50 mg) were weighed and transferred to a polypropylene tube. Immediately after weighing, $30 \%$ potassium hydroxide $(\mathrm{KOH})$ saturated with sodium sulfate $\left(\mathrm{Na}_{2} \mathrm{SO}_{4}\right)$ was added to the sample and the tubes were placed in boiling water for 30 mins. Glycogen content was precipitated from the sample by adding $95 \%$ ethanol, incubating the mixture on ice for 30 mins, and then centrifuging at $840 \mathrm{~g}$ for 30 mins. The supernatant was discarded and the precipitate was dissolved in $3 \mathrm{~mL}$ deionized water. Diluted glycogen $(250 \mu \mathrm{L})$ was then transferred to a new polypropylene tube and $750 \mu \mathrm{L}$ water was added (1:4 dilution) followed by $1 \mathrm{~mL} 5 \%$ phenol and $5 \mathrm{~mL} 96-98 \%$ sulfuric acid. The solution was mixed by gentle inversion and, after 10 mins of cooling, the tubes were transferred to a $25-30{ }^{\circ} \mathrm{C}$ water bath for 15 mins. Aliquots from each tube $(200 \mu \mathrm{L})$ were transferred to a 96-well plate in duplicate and the absorbance measured at $490 \mathrm{~nm}$ using a microplate reader (MultiskanGo, Thermo Fisher Scientific, Waltham, MA). Glycogen concentration was calculated using the following equation (Lo et al., 1970): glycogen (g)/ $100 \mathrm{~g}$ liver $=\left(\mathrm{A}_{290} / k\right) \times(V / v) \times\left(10^{-4} / w\right)$ where $\mathrm{A}_{290}$ is the absorbance at $490 \mathrm{~nm}, k$ is the slope of the standard curve, $\mathrm{V}$ is the total volume $(\mu \mathrm{L})$ of glycogen solution, $v$ is the volume $(\mu \mathrm{L})$ of the aliquot to which phenolsulfuric acid solution was added and $w$ is the mass of the liver sample in $\mathrm{g}$. The average intra-assay coefficient of variation was $1.36 \pm 0.78 \%$ for the duplicate measurements of each sample on the 96-well plate.

\subsection{Microbiome analysis}

Microbial DNA from frozen fecal contents isolated from the colon of 


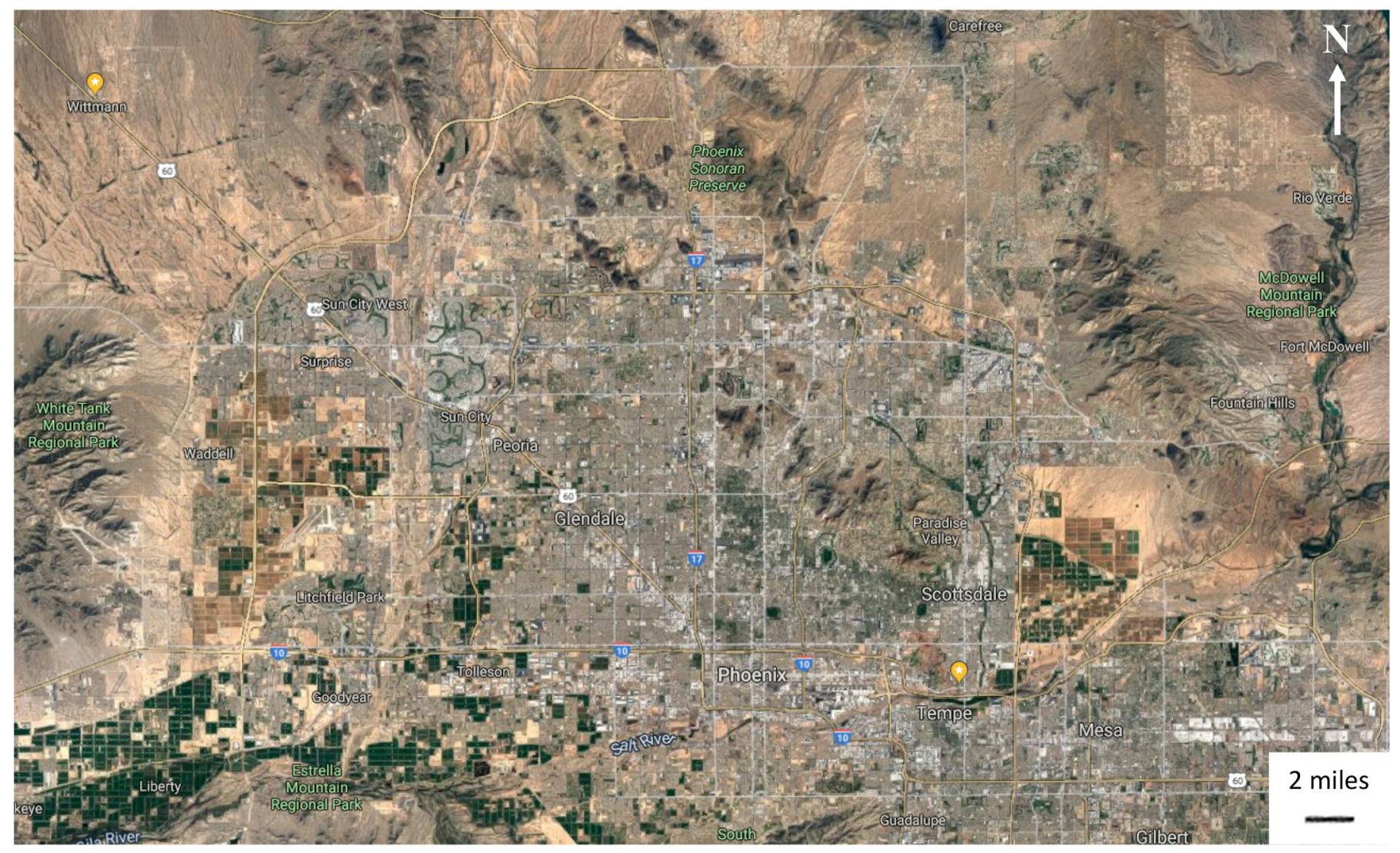

Fig. 1. Satellite image from Google Maps showing location of rural and urban capture sites (yellow balloons).

13 rural birds and 6 urban birds (fecal material was not present in the colon of 1 urban female) were extracted by using the PowerSoil ${ }^{\circledR}$ DNA Isolation Kit (MoBio, Carlsbad, CA, USA) following the manufacturer's protocol. Microbial DNA samples were sent to the Microbiome Core Facility in the Biodesign Institute at Arizona State University. The primer set 515f/806f designed by Caporaso et al. (2012) were used for the amplification sequencing of the V4 regions of the 16SrRNA gene. Each sample underwent PCR amplification and pooling. Next, samples were cleaned using the QIA quick PCR purification kit (QIAGEN, Valencia, CA, USA) then quantified using the Illumina library quantification Kit ABI Prism ${ }^{\circledast}$ (Kapa Biosystems, Wilmington, MA, USA). Following a series of dilutions and denaturing to a final concentration of 4 pM with a $30 \%$ PhiX solution, the DNA library was loaded into the Illumina MiSeq platform for analysis. QIIME analyses characterized the relative microbial abundances, which indicates how common a microbial taxa is relative to other taxa in a given sample (e.g. the proportion a microbe contributes to the larger microbial community). These data were also utilized in the online Galaxy tool, LEfSe, to examine differentially abundant taxa between urban and rural birds (Teyssier et al., 2018).

\subsection{Statistics}

Body mass and nutritional physiological variables - plasma glucose, uric acid, free glycerol and triglycerides and liver free glycerol, triglycerides and glycogen - were analyzed using two-way analyses of variance, with capture location and sex as fixed factors and their interaction included in the analysis (location*sex) with Tukey posthoc analyses. Shapiro-Wilk tests were used to determine normality of the data (SigmaPlot 14.0, Systat Software, San Jose, CA, USA). Abundance of individual microbes was determined relative to the abundance of total gut microbiota. A Mann-Whitney $U$ test was used to analyze effects of capture site, sex, and their interaction on the relative microbiome abundance at the phyla, class, order, and genus levels (SigmaStat 3.0; Systat Software Version 10.0, San Jose, CA, USA). To detect features that are statistically different among biological classes in fecal samples, LEfSe analysis uses the non-parametric Kruskal-Wallis sum-rank test. Next, it performs a Wilcoxon rank-sum test to assess biological consistency among groups. Lastly, the effect size of all differentially abundant features is determined using linear discriminant analysis (LDA) and visualized in a histogram (Segata et al., 2011). Statistical significance was accepted as $p<.05$.

\section{Results}

\subsection{Body mass}

There were no significant effects of sex (Fig. 2; two-way ANOVA, $\left.\mathrm{DF}=16 ; \quad p=.494, \quad \mathrm{j}_{\text {sex }}^{2}=0.023\right), \quad$ capture site $(p=.298$, \left.${\mathrm{y}_{\text {location }}}^{2}=0.055\right)$, or their interaction $\left(p=.073, \mathrm{\eta}_{\text {interaction }}{ }^{2}=0.173\right)$ on body mass. An analysis of effect sizes produced a Cohen's d statistic of 0.559 for all rural vs all urban body mass comparisons (i.e. grouped birds of both sexes). This represents a medium effect size.

\subsection{Plasma metabolites}

Plasma glucose concentrations from urban House Sparrows were significantly higher than those from rural birds (Fig. 3A; two-way ANOVA, DF $=16 ; p=.041, \mathrm{y}_{\text {location }}{ }^{2}=0.232$ ). However, we found no significant effects of sex $\left(p=.751, \mathrm{y}_{\mathrm{sex}}^{2}=0.005\right)$ or an interaction between sex and capture site $\left(p=.725, \mathrm{y}_{\text {interaction }}{ }^{2}=0.006\right)$ on plasma glucose concentration. Urban House Sparrows had significantly lower plasma concentrations of uric acid than rural sparrows (Fig. 3B; twoway ANOVA: $\mathrm{DF}=16 ; p=.026, \mathrm{y}_{\text {location }}{ }^{2}=0.264$ ), and again we did not find effects of sex $\left(p=.587, \mathrm{1}_{\mathrm{sex}}{ }^{2}=0.013\right)$ or an interaction between sex and location $\left(p=.950 \mathrm{y}_{\text {interaction }}{ }^{2}=0.000\right)$. Analysis of the 


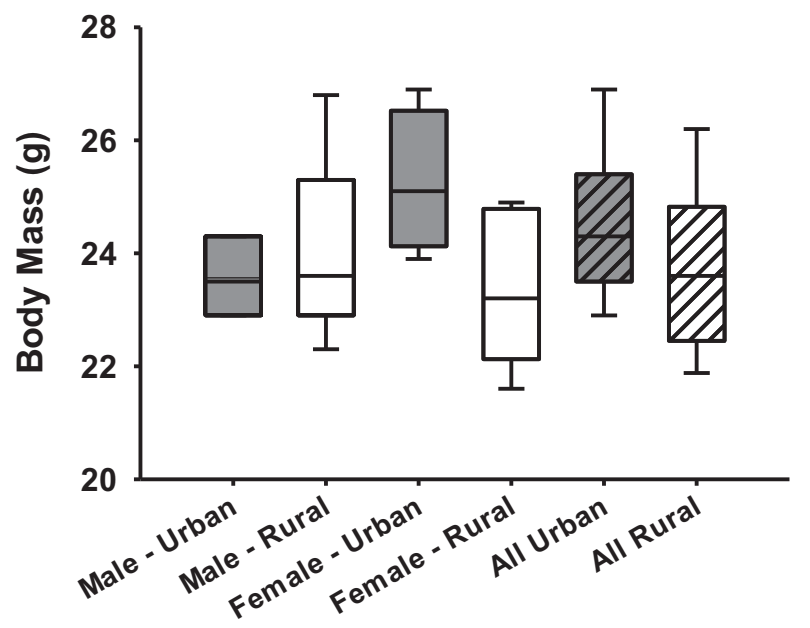

Fig. 2. Body mass for urban $(n=4 \mathrm{~F}, 3 \mathrm{M})$ and rural $(n=6 \mathrm{~F}, 7 \mathrm{M})$ House Sparrows. Data are expressed as mean \pm SEM. The boxes indicate the interquartile range, the horizontal line within the boxes denote the median and the whiskers extend from the maximum to minimum data points.

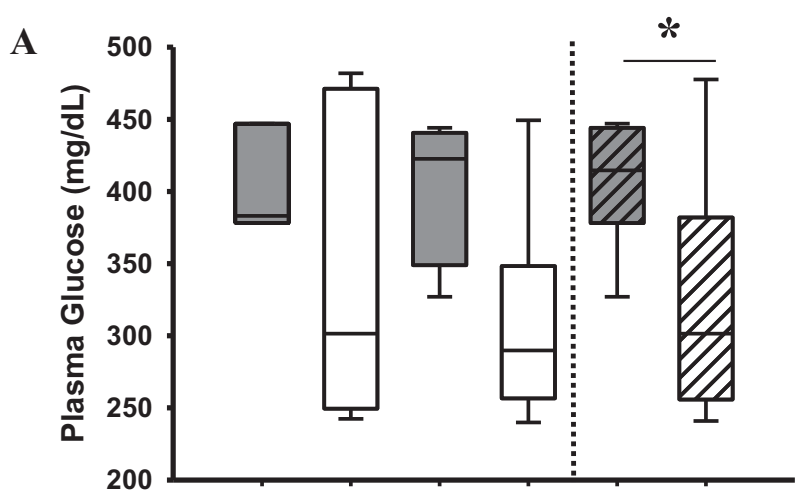

B

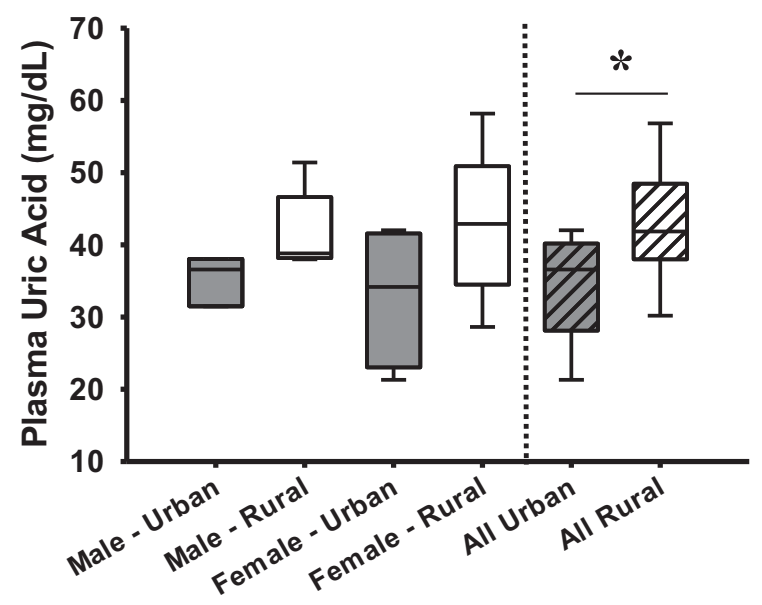

Fig. 3. Plasma glucose (A) and uric acid (B) concentrations in rural $(n=6 F$, $7 \mathrm{M})$ and urban $(\mathrm{n}=4 \mathrm{~F}, 3 \mathrm{M})$ House Sparrows. Data are expressed as mean \pm SEM. Two-way ANOVA, ${ }^{*} p<.05$. The boxes indicate the interquartile range, the horizontal line within the boxes denote the median and the whiskers extend from the maximum to minimum data points.

effect sizes resulted in Cohen's $\mathrm{d}=1.193$ and 1.271 for the comparison of all urban vs all rural plasma glucose and uric acid, respectively. Although the two-way ANOVA revealed a significant effect of the interaction between sex and location $(\mathrm{DF}=16 ; p=.048$,
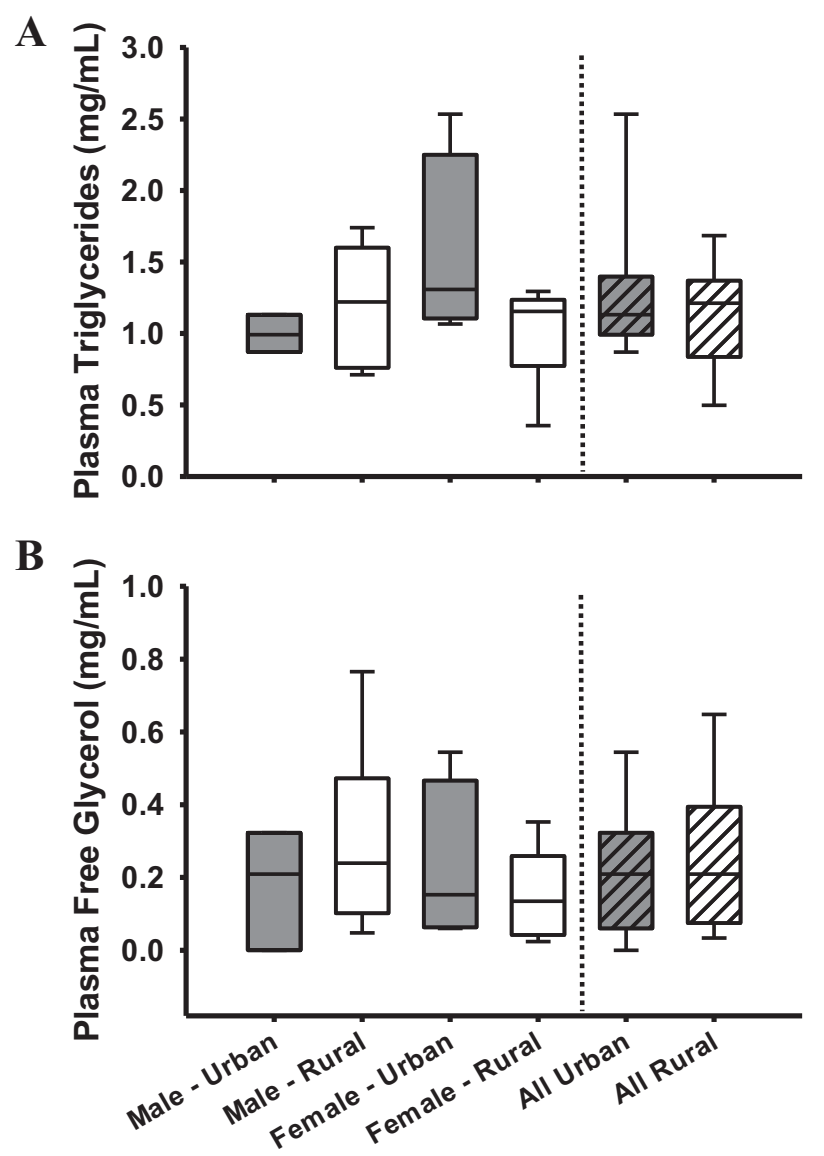

Fig. 4. Plasma triglyceride (A) and free glycerol (B) concentrations in rural $(\mathrm{n}=6 \mathrm{~F}, 7 \mathrm{M})$ and urban $(\mathrm{n}=4 \mathrm{~F}, 3 \mathrm{M})$ House Sparrows. Data are expressed as mean \pm SEM. The boxes indicate the interquartile range, the horizontal line within the boxes denote the median and the whiskers extend from the maximum to minimum data points.

$\mathrm{y}_{\text {interaction }}{ }^{2}=0.217$ ) on plasma triglycerides, Tukey post-hoc analyses showed only a non-significant trend for greater levels in urban as compared to rural female sparrows (Fig. 4A; $p=.068$ ). There were no significant effects of location $\left(p=.602, \eta_{\text {location }}{ }^{2}=0.013\right)$ or sex $\left(p=.580, \mathrm{y}_{\mathrm{sex}}{ }^{2}=0.015\right)$ on plasma triglycerides. There were no significant differences in plasma free glycerol concentrations between sexes and locations (Fig. 4B; two-way ANOVA; location $p=.706$, $\mathrm{\eta}_{\text {location }}{ }^{2}=0.008$; sex $p=.535, \mathrm{\eta}_{\text {sex }}^{2}=0.022$; interaction $p=.265$, $\mathrm{j}_{\text {interaction }}{ }^{2}=0.072$ ). Evaluation of the effect sizes resulted in Cohen's $\mathrm{d}=0.289$ and 0.200 (small effect) comparing all urban vs all rural plasma triglyceride and free glycerol, respectively.

\subsection{Liver metabolites}

Liver free glycerol concentrations were significantly lower in urban than rural House Sparrows (Fig. 5B; two-way ANOVA, DF $=16$; location $\mathrm{p}=.048, \mathrm{y}_{\text {location }}{ }^{2}=0.177$; $\operatorname{sex} p=.752, \mathrm{y}_{\text {sex }}{ }^{2}=0.004$; interaction $p=.053, \mathrm{y}_{\text {interaction }}{ }^{2}=0.168$ ). Tukey posthoc analyses revealed significantly higher liver free glycerol concentrations in male House Sparrows captured from rural versus urban locations $(p=.011)$ in addition to a trend for higher levels in rural males as compared to females. We found no significant differences in liver triglycerides (Fig. 5A) or liver glycogen (Fig. 5C) between urban and rural birds, nor an effect of sex or an interaction between sex and location on liver triglycerides. Examination of the effect sizes for all rural and all urban birds (combined sexes), resulted in a Cohen's d statistic of 0.496 (medium effect), 0.903 (large effect), and 0.511 (medium effect) for liver triglyceride, 
A

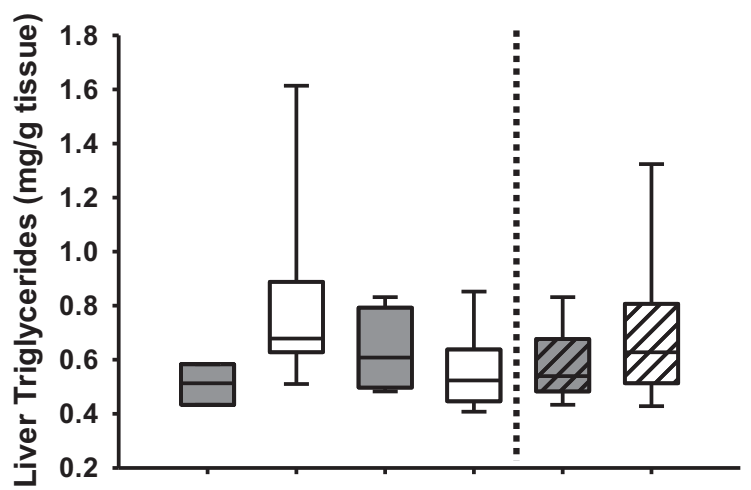

B

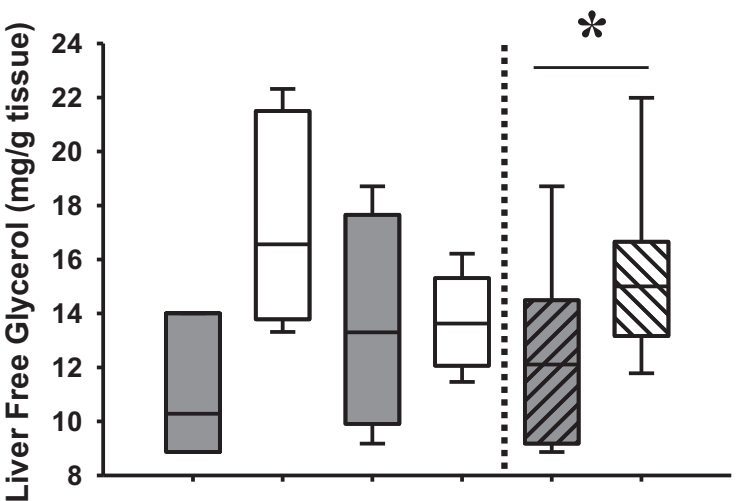

C

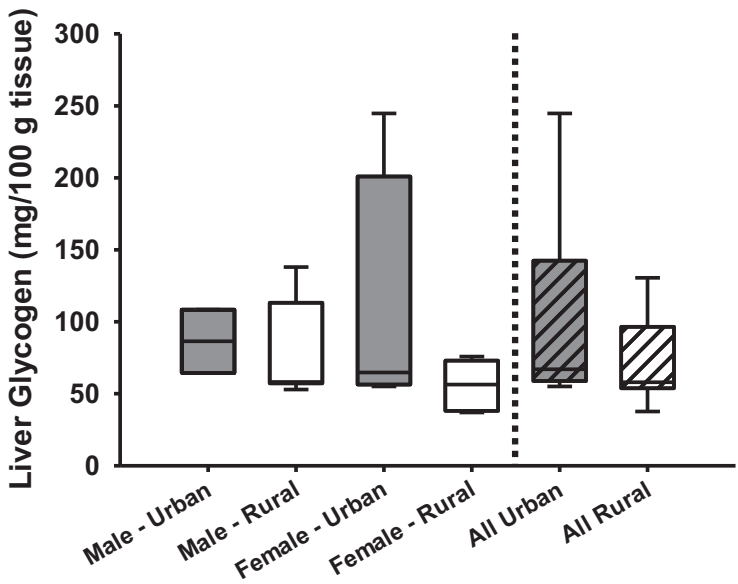

Fig. 5. Liver triglyceride (A), free glycerol (B) and glycogen concentrations (C) in rural $(\mathrm{n}=6 \mathrm{~F}, 7 \mathrm{M})$ and urban $(\mathrm{n}=4 \mathrm{~F}, 3 \mathrm{M})$ House Sparrows. Data are expressed as means \pm SEM. Two-way ANOVA, ${ }^{*} \mathrm{p}<.05$. The boxes indicate the interquartile range, the horizontal line within the boxes denote the median and the whiskers extend from the maximum to minimum data points.

free glycerol, and glycogen, respectively.

\subsection{QIIME and LEfSe analyses}

There were no significant differences in the relative phylum abundance of gut bacteria between urban and rural House Sparrows (Fig. 6): Unassigned (Mann-Whitney $\mathrm{U}=40.50, p=.930$ ), Crenarchaeota $(\mathrm{U}=32.50, p=.174)$, Euryachaeota $(\mathrm{U}=42.00, p=.571)$, Acidobacteria ( $\mathrm{U}=42.00, p=.571)$, Actinobacteria $(\mathrm{U}=41.50, p=.860)$, Bacteroidetes ( $\mathrm{U}=48.00, p=.239)$, Chloroflexi $(\mathrm{U}=54.00, p=.100)$, Cyanobacteria $(\mathrm{U}=39.00, p=.965)$, Firmicutes $(t=0.459, p=.652)$, Proteobacteria $(\mathrm{U}=37.00, p=.895)$, TM6 $(\mathrm{U}=42.00, p=.571$ and Tenericutes $(\mathrm{U}=35.00, p=.710)$. However, effect size estimates determined using LEfSe analyses showed that the gut microbiome of urban House Sparrows had significantly greater abundance of Pseudomonadales, Williamsia, Williamssiaceae, Pseudomonas, and Pseudomonadaceae (Fig. 6, LDA > 2.0:5), relative to rural House Sparrows. The figure shows effect sizes for taxa that are significantly increased in the urban birds compared to the rural birds.

\section{Discussion}

The objective of this study was to compare the nutritional physiology and gut microbiome of House Sparrows captured from urban and rural locations. Several studies have shown that urban House Sparrows weigh less and are in poor body condition compared to rural conspecifics, which may contribute to population declines in urban sparrows (Dulisz et al., 2016; Liker et al., 2008; Meillère et al., 2015; Vangestel et al., 2010). Although body mass was not significantly different between the urban and rural birds examined in this study, several notable differences in plasma metabolites and gut microbiota were observed. Specifically, our results show that urban House Sparrows had higher plasma glucose, lower plasma uric acid and liver free glycerol concentrations, as well as greater abundance of taxa within the phylum Proteobacteria compared to rural birds.

Our observation that plasma glucose concentrations were higher in urban birds when compared to rural birds is consistent with the idea that urbanization promotes high blood glucose in birds. This finding is interesting, as birds in general tend to present very high blood sugar concentrations (Braun and Sweazea, 2008). Moreover, Herrera-Duenas et al. (2017) found that urban House Sparrows have higher oxidative stress, which they attributed to low diet quality. Uric acid is the most abundant antioxidant found in birds (Seaman et al., 2008; Stinefelt et al., 2005; Machin et al., 2004; Simoyi et al., 2002; Klandorf et al., 2001). As such, the lower levels measured in urban House Sparrows in the current study combined with their elevated plasma glucose may increase their risk of oxidative stress, as pharmacological inhibition of uric acid production increases oxidative stress in birds (Klandorf et al., 2001). For this reason, some researchers regard plasma uric acid concentrations as a biomarker of oxidative stress in birds (Tsahar et al., 2006; Cohen et al., 2009). However, other explanations for the reduced plasma uric acid in urban sparrows should be considered. First, as the main end-product of nitrogen catabolism, these differences in plasma uric acid could simply indicate differences in protein intake, with urban birds consuming diets with less protein than rural conspecifics (Cohen et al., 2009; Machin et al., 2004; Tsahar et al., 2006). Second, uric acid is converted to allantoin when used as an antioxidant. Thus, it is possible that the lower levels in urban House Sparrows may be reflecting greater conversion of uric acid to allantoin, thereby reducing circulating concentrations (Tsahar et al., 2006). In addition, Cohen et al. (2008) demonstrated that increases in uric acid concentrations can also indicate recent stress, poor body condition, as well as potential compensatory mechanisms, all factors that may have contributed to the present observations.

The observed lower levels of free glycerol in the liver of male urban House Sparrows compared to rural male conspecifics may reflect reduced dietary intake of fats, lower hydrolysis of triglycerides, or increased utilization of free glycerol for gluconeogenesis. The latter is consistent with the observed elevations in glucose concentrations in the urban birds. Male House Sparrows captured from rural areas also tended to have higher liver free glycerol concentrations compared to females. Although not significant, $20.6 \%$ of the variation in liver free glycerol could be explained by sex differences in the rural birds. Moreover, fatty acids are used to support long-distance flight in birds (Jenni-Eiermann et al., 2002). Thus, it is possible that the higher levels of liver free glycerol in rural sparrows reflect longer distance flights in these birds, perhaps for foraging purposes, dispersal or escaping predation. Food sources may be more readily available to urban House Sparrows, resulting in more frequent short-distance flights that are 

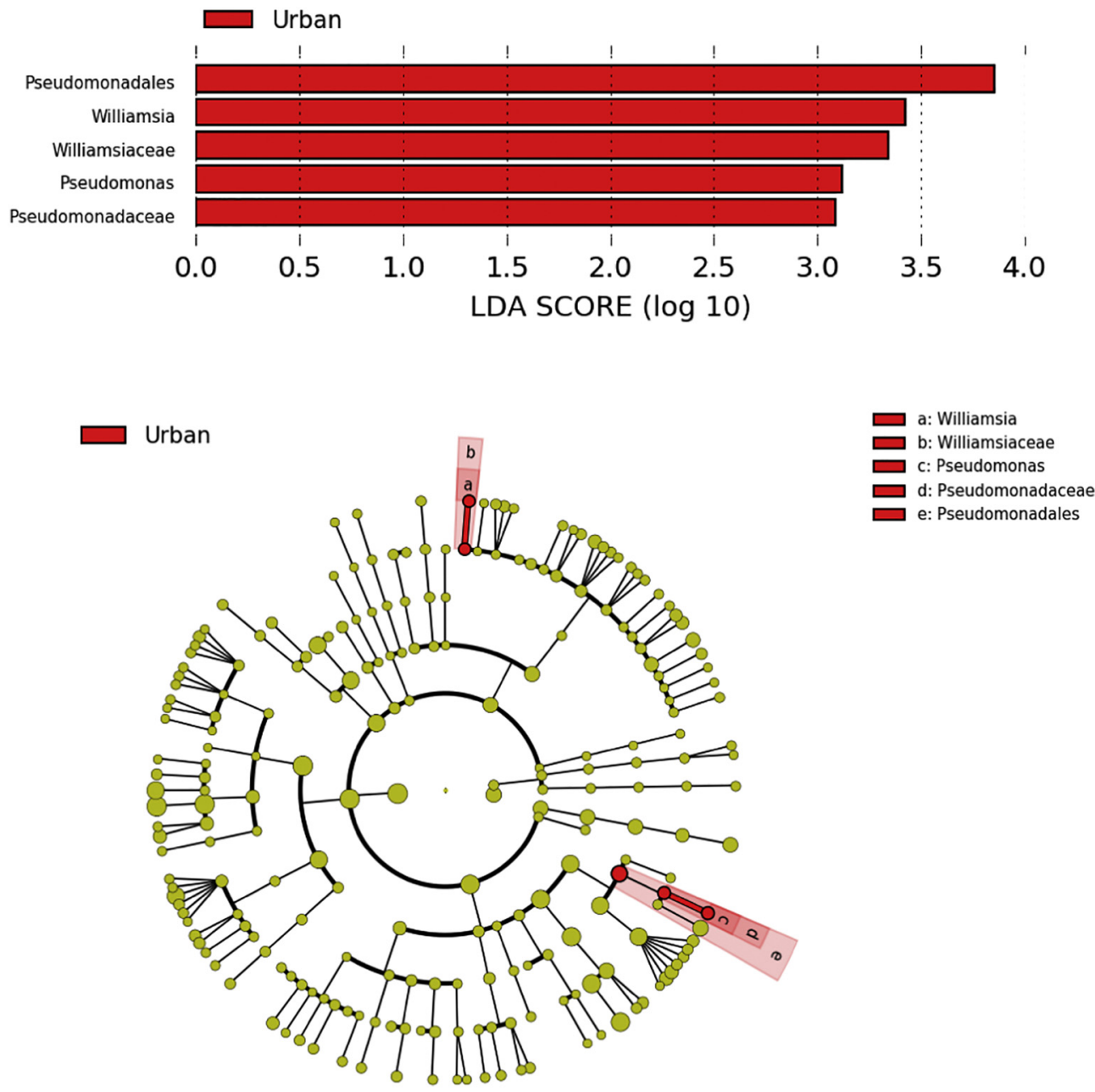

Fig. 6. Top panel: Differentially abundant gut microbial taxa in urban and rural House Sparrows were identified through LEfSe analyses. The histogram shows the bacteria in red bars that were significantly greater in the fecal samples of urban House Sparrows $(n=6)$ compared to rural House Sparrows ( $n=13$ ). The $x$-axis shows the LDA score which represents the log10-adjusted effect size of microbial taxa between urban and rural House Sparrows (LDA score > 2.0:5) Bottom panel: The cladogram depicts the phylogenic relationship between microbial taxa that were higher in urban House Sparrows. The nodes represent a common ancestor.

fueled primarily by carbohydrates (Rothe et al., 1987).

LEfSe analyses showed a significantly higher abundance of taxa (Pseudomonadales, Williamsia, Williamsiaceae, Pseudomonas and Pseudomonadaceae) within the phylum Proteobacteria in urban birds. This is consistent with prior research by Miron et al. (2014), who found that the gut microbiome profile along the intestinal tract of two House Sparrows was comprised mainly of Firmicutes and Proteobacteria. Although, the results differ from Teyssier et al. (2018) who observed no significant differences in Proteobacteria in urban House Sparrows living in Belgium. Rather, Actinobacteria abundance was lower in those urban sparrows (Teyssier et al., 2018). In general, gut microbial diversity appears to be related to the relative abundance of nutrients ingested by birds (Miron et al., 2014). In fact, gut commensal bacteria aid their hosts in essential biochemical processing, such as polysaccharide break down. Such processes are necessary to harness energy from diets (Bäckhed et al., 2004). Thus, the variations in the presence of gramnegative Proteobacteria observed in the present study are consistent with variation in the nutritional physiology of House Sparrows from urban and rural locations, as increased abundance of Proteobacteria is associated with consumption of diets high in saturated fats and carbohydrates (i.e. the so-called Western diet; Agus et al., 2016). Additionally, Proteobacteria are prevalent in the gut microbiome of humans and are associated with several notable human pathogens, including Brucella, Rickettsia, Bordetella, Neisseria, Escherichia, Shigella, Salmonella, Yersinia, and Helicobacter (Rizzatti et al., 2017). The notable switch towards a higher prevalence of Proteobacteria in the urban birds examined in the present study demonstrates that urbanization promotes a shift in the gut microbiome that may impact other nutritional physiology outcomes.

Limitations of the study include lack of information on other factors associated with urbanization that could contribute to the observed differences in plasma metabolites and the gut microbiome between the two populations. These factors include light, noise and other pollutants, water quality as well as the potential effects of urban heat islands. Since water quality near capture sites was not measured in the present study, it is not possible to assess whether this factor contributed to the observed differences in the gut microbiome of urban House Sparrows. Moreover, temperature-induced stress may also contribute to variation in the nutritional physiology and gut microbiome composition of the urban individuals.

In summary, data from the present study show location-related variation in the nutritional physiology and gut microbiota of wildcaught House Sparrows and highlight the potential dietary and ecological impacts of urbanization in these birds. Further work is needed to understand how these endogenous changes might ultimately impact avian health and fitness.

\section{Acknowledgements}

We thank Sisi Gao for assistance in trapping urban birds. This 
research was supported in part by funds from the School of Life Sciences Undergraduate Research (SOLUR) Program through the School of Life Sciences at Arizona State University as well as Barrett, the Honors College (both to AG).

\section{Declaration of Competing Interest}

\section{The authors declare no conflicts of interest.}

\section{References}

Agus, A., Denizot, J., Thévenot, J., Martinez-Medina, M., Massier, S., Sauvanet, P., Bernalier-Donadille, A., Denis, S., Hofman, P., Bonnet, R., Billard, E., Barnich, N., 2016. Western diet induces a shift in microbiota composition enhancing susceptibility to adherent-Invasive E. coli infection and intestinal inflammation. Sci. Rep. 6, 19032.

Aronson, M.F.J., La Sorte, F.A., Nilon, C.H., Katti, M., Goddard, M.A., Lepczyk, C.A., Warren, P.S., Williams, N.S.G., Cilliers, S., Clarkson, B., Dobbs, C., Dolan, R., Hedblom, M., Klotz, S., Kooijmans, J.L., Kuhn, I., MacGregor-Fors, I., McDonnell, M., Mortberg, U., Pysek, P., Siebert, S., Sushinsky, J., Werner, P., Winter, M., 2014. A global analysis of the impacts of urbanization on bird and plant diversity reveals key anthropogenic drivers. Proc. Biol. Sci. 281 (1780), 20133330.

Bäckhed, F., Ding, H., Wang, T., Hooper, L.V., Koh, G.Y., Nagy, A., Semenkovich, C.F., Gordon, J.I., 2004. The gut microbiota as an environmental factor that regulates fat storage. Proc. Natl. Acad. Sci. U. S. A. 101 (44), 15718-15723.

Caporaso, J.G., Lauber, C.L., Walters, W.A., Berg-Lyons, D., Huntley, J., Fierer, N., Owens, S.M., Betley, J., Fraser, L., Bauer, M., Gormley, N., Gilbert, J.A., Smith, G., Knight, R., 2012. Ultra-high-throughput microbial community analysis on the Illumina HiSeq and MiSeq platforms. ISME J. 6 (8), 1621-1624.

Cohen, A., Hau, M., Wikelski, M., 2008. Stress, metabolism, and antioxidants in two wild passerine bird species. Physiol. Biochem. Zool. 81 (4), 463-472.

Cohen, A., McGraw, K.J., Robinson, W.D., 2009. Serum antioxidant levels in wild birds vary in relation to diet, season, life history strategy, and species. Oecologia. 161 (4), $673-683$.

Cowie, R.J., Hinsley, S.A., 1988. The provision of food and the use of bird feeders in suburban gardens. Bird Study. 35, 163-168.

Cox, D.T.C., Gaston, K.J., 2016. Urban bird feeding: connecting people with nature. PLoS One 11 (7), e0158717.

Davies, Z.G., Fuller, R.A., Loram, A., Irvine, K.N., Sims, V., Gaston, K.J., 2009. A national scale inventory of resource provision for biodiversity within domestic gardens. Biol. Conserv. 142, 761-771.

Dulisz, B., Nowakowski, J.J., Gornik, J., 2016. Difference in biometry and body condition of the house sparrow (Passer domesticus) in urban and rural population during breeding season. Urban Ecosyst. 19 (3), 1307-1324.

Evans, K.L., Newson, S.E., Gaston, K.J., 2009. Habitat influences on urban avian assemblages. Ibis. 151, 19-39.

Francis, M.L., Plummer, K.E., Lythgoe, B.A., Macallan, C., Currie, T.E., Blount, J.D., 2018. Effects of supplementary feeding on interspecific dominance hierarchies in garden birds. PLoS One 13 (9), e0202152.

Galbraith, J.A., Beggs, J.R., Jones, D.N., McNaughton, E.J., Krull, C.R., Stanley, M.C., 2014. Risks and drivers of wild bird feeding in urban areas of New Zealand. Bio. Conserv. 180, 64-74.

Galbraith, J.A., Beggs, J.R., Jones, D.N., Stanley, M.C., 2015. Supplementary feeding restructures urban bird communities. Proc. Natl. Acad. Sci. U. S. A. 112 E2648-E2657.

Gavett, A.P., Wakeley, J.S., 1986. Diets of house sparrows in urban and rural habitats. Wilson Bull. 98 (1), 137-144.

Herrera-Duenas, A., Pineda-Pampliega, J., Antonio-Garcia, M.T., Aguirre, J.I., 2017. The influence of urban environments on oxidative stress balance: a case study on the house sparrow in the Iberian Peninsula. Front. Ecol. Evol. 5 (Article 106).

Jenni-Eiermann, S., Jenni, L., Kvist, A., Lindstrom, A., Piersma, T., Visser, G.H., 2002 Fuel use and metabolic response to endurance exercise: a wind tunnel study of a longdistance migrant shorebird. J. Exp. Biol. 205 (Pt 16), 2453-2460.

Klandorf, H., Rathore, D.S., Iqbal, M., Shi, X., VanDyke, K., 2001. Accelerated tissue aging and increased oxidative stress in broiler chickens fed allopurinol. Comp. Biochem. Physiol. (2), 93-104 129C.

Liker, A., Papp, Z., Bokony, V., Lendvai, A.Z., 2008. Lean birds in the city: body size and condition of house sparrows along the urbanization gradient. J. Anim. Ecol. 77 (4), $789-795$.

Lo, S., Russell, J.C., Taylor, A.W., 1970. Determination of glycogen in small tissue samples. J. Appl. Physiol. 28 (2), 234-236.

Machin, M., Simoyi, M., Blemings, K., Klandorf, H., 2004. Increased dietary protein elevates plasma uric acid and is associated with decreased oxidative stress in rapidlygrowing broilers. Comp. Biochem. Physiol. 383-390 137B.

Martin, L.B., Fitzgerald, L., 2005. A taste for novelty in invading house sparrows, Passer domesticus. Behav. Ecol. 16 (4), 702-707.

Martinson, T.J., Flaspohler, D.J., 2003. Winter bird feeding and localized predation on simulated bark-dwelling arthropods. Wildl. Soc. Bull. 510-516, 2003.

Meillère, A., Brischoux, F., Parenteau, C., Angelier, F., 2015. Influence of urbanization on body size, condition, and physiology in an urban exploiter: a multi-component approach. PLoS One 10 (8), e0135685.

Miron, L., Mira, A., Rocha-Ramirez, V., Belda-Ferre, P., Cabrera-Rubio, R., Folch-Mallol, J., Cardenas-Vazquez, R., DeLuna, A., Hernandez, A.L., Maya-Elizarraras, E., Schondube, J.E., 2014. Gut Bacterial Diversity of the House Sparrow (Passer domesticus) Inferred by $16 \mathrm{~S}$ rRNA Sequence Analysis. (Metagenomics. 3, Article ID 235853).

Norris, A.W., Chen, L., Fisher, S.J., Szanto, I., Ristow, M., Jozsi, A.C., Hirshman, M.F., Rosen, E.D., Goodyear, L.J., Gonzalez, F.J., Spiegelman, B.M., Kahn, C.R., 2003. Muscle-specific PPARgamma-deficient mice develop increased adiposity and insulin resistance but respond to thiazolidinediones. J. Clin. Invest. 112 (4), 608-618.

Pollack, L., Ondrasek, N.R., Calisi, R., 2017. Urban health and ecology: the promise of an avian biomonitoring tool. Curr. Zool. 63 (2), 205-212.

Rizzatti, G., Lopetuso, L.R., Gibiino, G., Binda, C., Gasbarrini, A., 2017. Proteobacteria: a common factor in human diseases. Biomed. Res. Int. 2017 (Article ID 9351507).

Rothe, H.J., Biesel, W., Nachtigall, W., 1987. Pigeon flight in a wind tunnel. J. Comp. Physiol. (1), 99-109 157B.

Seaman, C., Moritz, J., Falkenstein, E., VanDyke, K., Casotti, G., Klandorf, H., 2008 Inosine ameliorates the effects of hemin-induced oxidative stress in broilers. Comp. Biochem. Physiol. 670-675 151A.

Simoyi, M., VanDyke, K., Klandorf, H., 2002. Manipulation of plasma uric acid in broiler chicks and its effect on leukocyte oxidative activity. Am. J. Physiol. Regul. Integr. Comp. Physiol. 282, 791-796.

Stinefelt, B., Leonard, S.S., Blemings, K.P., Shi, X., Klandorf, H., 2005. Free radical scavenging, DNA protection, and inhibition of lipid peroxidation mediated by uric acid. Ann. Clin. Lab. Sci. 35, 37-45.

Teyssier, A., Rouffaer, L.O., Saleh Hudin, S., Strubbe, D., Matthysen, E., Lens, L., White, J., 2018. Inside the guts of the city: urban-induced alterations of the gut microbiota in a wild passerine. Sci. Total Environ. 612, 1276-1286.

Tsahar, E., Arad, Z., Izhaki, I., Guglielmo, C.G., 2006. The relationship between uric acid and its oxidative product allantoin: a potential indicator for the evaluation of oxidative stress in birds. J. Comp. Physiol. 653-661 176B.

United Nations, 2018. World Urbanization Prospects: 2018 Revision Highlights. Population Division of the United Nations Department of Economic and Social Affairs. United Nations, New York.

Vangestel, C., Braeckman, B.P., Matheve, H., Lens, L., 2010. Constraints on home range behaviour affect nutritional condition in urban house sparrows (Passer domesticus). Biol. J. Linn. Soc. 101, 41-50. 